\title{
Menstrual Hygiene Practices among Adolescent School Girls in Pakistan
}

\author{
Naveed Mansoori ${ }^{1}$, Hiba Tanweer ${ }^{2}$, Imtiaz Ahmed ${ }^{3}$, Abdullah $^{4}$, \\ Itesham Noor ${ }^{5}$ and Syed Muhammad Mubeen ${ }^{6}$
}

\begin{abstract}
Objectives: To evaluate menstrual hygiene practices among teenage girls and to compare menstrual hygiene practices among secondary and higher secondary school girls in Pakistan

Methodology: A cross-sectional study of adolescent girls (grades 9 to 12) from different secondary and higher secondary schools across Pakistan was conducted between November 2017 and September 2018. A pre-tested and standardized questionnaire was administered using a non-probability sampling technique. The menstrual hygiene practices were evaluated and comparisons were made between secondary and higher secondary school girls about these practices. Data was analysed using SPSS version 22. P-value $<0.05$ was set for being statistically significant.

Results: Out of a total of 2,000 adolescent girls, an equal number of adolescent girls $(n=1,000)$ were chosen from secondary and higher secondary schools. The mean menarchal age was $12.5 \pm 1.2$ years. Majority of the participants $(63.6 \%)$ belonged to public sector schools and $(71.3 \%)$ responded that menstrual blood comes from the womb. One in five (19.3\%) girls missed 2 days/month of school due to pain (54.5\%). Two-thirds $(68.6 \%)$ of the participants were using sanitary pads and one of three changed their pads three times/day, and forty-six percent of the girls were unable to carry out daily activities due to menstrual period. Statistically significant $(\mathrm{P}<0.05)$ association was observed between knowledge of menstruation among secondary and higher secondary school girls.

Conclusion: The study showed that menstrual hygiene was understood well among young girls. However, a substantial association was noted between secondary and higher secondary school girls' hygiene practices.
\end{abstract}

Key words: Adolescent girls, Menstruation hygiene practices, Schools, Pakistan

How to cite this article: Mansoori N, Tanweer H, Ahmed I, Abdullah, Noor I, Mubeen SM. Assessment of menstrual hygiene practices among adolescent school girls in Pakistan. Ann Jinnah Sindh Med Uni 2020; 6(2):44-49

DOI: https://doi.org/10.46663/ajsmu.v6i2.44-49

1 Associate Professor, Department of Community Health Sciences, Hamdard College of Medicine \& Dentistry, Hamdard University, Karachi, Pakistan

2 House Officer, Hamdard University Hospital, Karachi, Pakistan

3 House Officer, Sheikh Zayed Hospital, Rahim Yar Khan, Pakistan

4 House Officer, Hayatabad Medical Complex, Peshawar, Pakistan

5 House Officer, Bacha Khan Medical Complex, Swabi, KPK, Pakistan

6 Professor, Department of Community Health Sciences, Hamdard College of Medicine \& Dentistry, Hamdard University, Karachi, Pakistan

Correspondence: Naveed Mansoori, Associate Professor, Department of Community Health Sciences, Hamdard College of Medicine \& Dentistry, Hamdard University, Karachi, Pakistan

Email: naveedmansuri81@gmail.com

\section{INTRODUCTION}

Menstrual hygiene is one of the problems for young girls in middle-and low-income countries, particularly when in school ${ }^{1}$. Several factors including the female's knowledge influence menstruation ${ }^{2}$. Poor water sources, sanitation and hygiene facilities at schools, education in puberty and insufficient hygiene procedures make it humiliating and painful for adolescent girls to undergo menstruation ${ }^{3}$.

Lack of knowledge about menstruation is associated with profound psychological and emotional problems ${ }^{4}$. Many schools do not help adolescent girls in maintaining menstrual hygiene that causes stress and humiliation dealing with blood-stained clothing ${ }^{5}$. Also it may lead to development of urinary and genital infections and even possibly infertility ${ }^{6,7}$.

UNICEF reports that one girl out of ten does not go to school during her monthly cycle. 
Likewise, World Bank figures suggest that girls were absent from school every four days due to menstruation ${ }^{8}$. Statistics from India have shown that out of 113 million, 68 million adolescent girls go to schools, with inadequate menstrual hygiene habits and cultural taboos being considered the main barriers to school attendance ${ }^{9,10}$. Use of sanitary pads amongst Tanzanian women was found to be only $18 \%$, while remaining others were using toilet paper or $\operatorname{cloth}^{11}$. A study among Nigerian school girls found that $56 \%$ were utilizing pieces of cloth and toilet paper instead of menstrual pads ${ }^{12}$. In Ethiopia, it was found that most of the school girls knew about menstrual cycle before menarche, however only $37.6 \%$ used sanitary napkins, and a substantial proportion, 62.4 percent used rags and bits of cloth ${ }^{13}$, and $11 \%$ changed their menstrual cloth once a day ${ }^{14}$.

In Pakistan, many traditional and religious factors impose restrictions on social lives of women. Cultural taboos, misconceptions, isolation and restrictions regarding menstruating girls and menstrual hygiene prevent them from seeking help and restrain them from physical activities when menstruating ${ }^{15}$.

Menstrual hygiene is a very significant factor in reproductive tract infections and a crucial element of teenage girls' health education. A study found that girls' anxiety and embarrassment from blood and body odor leakage is a major cause of school absenteeism and dropouts. ${ }^{16}$ Most school girls do not have the resources for their own care and do not seek the help they need when facing problems, which not only hampers their ability to carry out daily activities but it can also lay the foundation for life long debilitation.

In Pakistan, studies regarding menstrual hygiene practices are scarce. This study aims to evaluate menstrual hygiene practices among teenage girls and to compare menstrual hygiene practices among secondary and higher secondary school girls in Pakistan.

\section{METHODOLOGY}

A cross-sectional analysis of adolescent school girls from different Pakistani provinces (Sindh, Punjab, Baluchistan, and Khyber Pakhtunkhwa) was done from November 2017 to September 2018. A total of 2000 girls (1000 from secondary and 1000 from higher secondary schools) who accepted and agreed to participate were interviewed. Using non-probability convenient sampling technique, post menarche girls from grades 9 to 12 were included. Girls who were not physically or mentally fit on the day of data collection were excluded. Hamdard College of Medicine $\&$ Dentistry Ethics Committee gave the approval to conduct the study.
The data was collected using structured, selfadministered questionnaire written in English. To ensure its understanding it was translated in local language (Urdu) by a language professional. The questionnaire was validated and used in other studies previously to assess the menstrual hygiene practices among school girls 17 . Pilot study was carried out on $5 \%$ of the sample and relevant amendments were made.

After taking approval from the schools' administrators, girls are provided the questionnaire with their consent. Before the questionnaire was administered, the respondents were briefed about the intent and various aspects of the study. The responses from each class were taken separately in their dedicated sessions. Participants were asked to read each statement carefully and respond objectively. Girls also had the opportunity to ask questions. They were briefed that participants' identity would remain confidential, data cannot be traced back to participants, and it will only be used for research purpose.

The data was cleaned, coded and entered in SPSS version 22 after ensuring completeness of the filled forms. Descriptive statistics were done for all independent variables and Chi-square test measured inferential statistics to analyze the association of knowledge of menstrual hygiene activities between secondary and higher secondary school girls. Difference between types of absorbent material used during periods among secondary and high schools' girls was also determined. A p-value $<0.05$ was considered as statistically significant. Binary logistic regression was applied to estimate the effect of different activities missed during menstruation. Multiple logistic regression analysis selected relevant variables to determine the adjusted odds ratio (OR).

\section{RESULTS}

Out of total 2000 adolescent girls, equal number of adolescent girls $(\mathrm{n}=1000)$ were selected from secondary and higher secondary schools. The mean age of the participants was $16.1 \pm 1.8$ years. More than half of the participants 1,272 (63.6\%) belonged to public sector schools. The mean age at menarche was $12.5 \pm 1.2$ years. In terms of knowledge of menstruation, 1,793 $(89.7 \%)$ participants replied that women stopped menstruation as they grew old, 1,502 (75\%) thought that menstruation was a disease, $1,461(73 \%)$ said that pregnant women menstruate, $1,551(77.5 \%)$ thought that menstrual blood comes from the gastrointestinal tract where food is processed, $1,425(71.3 \%)$ replied that menstrual blood comes from the womb, 1,158 (58\%) believed that menstrual blood contains dangerous 
substances, 1,327 (66.4\%) thought that pain during periods implies that somebody is not well and 1000 $(50.0 \%)$ thought it was unsafe for a female's body if she runs during her menstruation cycle. A statistically significant $(\mathrm{p}<0.05)$ relationship was found between secondary and higher secondary school girls' knowledge of menstruation. (Table 1) with secondary and higher secondary school girls. The response that periods make you unable to walk far $1,130(56.5 \%)$, was negatively associated with secondary and higher secondary school girls with $\mathrm{OR}=0.81,95 \% \mathrm{CI}=0.68-0.98, \mathrm{p}<0.05$.

Table 1: Difference of Knowledge Regarding Menstruation Between Secondary and Higher Secondary School Girls

\begin{tabular}{|c|c|c|c|c|c|}
\hline \multicolumn{2}{|l|}{$\begin{array}{l}\text { Knowledge About } \\
\text { Menstruation }\end{array}$} & \multirow{2}{*}{$\begin{array}{l}\text { Secondary School } \\
\text { n (\%) } \\
864(86.4)\end{array}$} & \multirow{2}{*}{$\begin{array}{c}\text { Higher Secondary } \\
\text { School } \\
\text { n }(\%) \\
929(92.9)\end{array}$} & \multirow{2}{*}{$\begin{array}{c}\text { Total } \\
\text { n (\%) } \\
1793(89.7)\end{array}$} & \multirow{3}{*}{$\begin{array}{l}\text { p-value } \\
<0.001 *\end{array}$} \\
\hline \multirow{2}{*}{$\begin{array}{l}\text { Menstruation stops } \\
\text { in very old women. }\end{array}$} & Yes & & & & \\
\hline & No & $136(13.6)$ & $71(7.1)$ & $207(10.3)$ & \\
\hline \multirow[t]{2}{*}{ Menstruation is a disease. } & Yes & $385(38.5)$ & $113(11.3)$ & $498(24.9)$ & \multirow[b]{2}{*}{$<0.001 *$} \\
\hline & No\# & $615(61.5)$ & $887(88.7)$ & $1502(75.1)$ & \\
\hline \multirow[t]{2}{*}{ Pregnant women menstruate. } & Yes & $432(43.2)$ & $107(10.7)$ & $539(27.0)$ & \multirow[b]{2}{*}{$<0.001 *$} \\
\hline & No\# & $568(56.8)$ & $893(89.3)$ & $1461(73.1)$ & \\
\hline \multirow{2}{*}{$\begin{array}{l}\text { Source of menstrual blood } \\
\text { is stomach where the food is processed. }\end{array}$} & Yes & $340(34.0)$ & $109(10.9)$ & $449(22.5)$ & \multirow[b]{2}{*}{$<0.001 *$} \\
\hline & No\# & $660(66.0)$ & $891(89.1)$ & $1551(77.5)$ & \\
\hline \multirow[t]{2}{*}{ Source of menstrual blood is womb. } & Yes\# & $648(64.8)$ & $777(77.7)$ & $1425(71.3)$ & \multirow[b]{2}{*}{$<0.001 *$} \\
\hline & No & $352(35.2)$ & $223(22.3)$ & $575(28.7)$ & \\
\hline \multirow{2}{*}{$\begin{array}{l}\text { Menstrual blood contains } \\
\text { dangerous substances. }\end{array}$} & Yes & $567(56.7)$ & $275(27.5)$ & $842(42.1)$ & \multirow[b]{2}{*}{$<0.001 *$} \\
\hline & No\# & $433(43.3)$ & $725(72.5)$ & $1158(57.9)$ & \\
\hline \multirow{2}{*}{$\begin{array}{l}\text { Menstruation pain means } \\
\text { that someone is not well. }\end{array}$} & Yes & $512(51.2)$ & $161(16.1)$ & $673(33.6)$ & \multirow[b]{2}{*}{$<0.001 *$} \\
\hline & No\# & $588(48.8)$ & $839(83.9)$ & $1327(66.4)$ & \\
\hline \multirow{2}{*}{$\begin{array}{l}\text { Running during menstrual } \\
\text { cycle is harmful. }\end{array}$} & Yes & $631(63.1)$ & $369(36.9)$ & $1000(50.0)$ & \multirow[b]{2}{*}{$<0.001 *$} \\
\hline & No\# & $369(36.9)$ & $631(63.1)$ & $1000(50.0)$ & \\
\hline
\end{tabular}

$*$ p-value $<0.05$

\#correct response

Most of the participants 385 (19.3\%) missed two days of school in a month and the reasons of missing school by majority of them $1,089(54.5 \%)$ were pain during menstruation and the fear of staining clothes 368 (18.4\%). Absorbent material used by most of the participants $1,371(68.6 \%)$ were sanitary pads and onethird of them $704(35.2 \%)$ changed their pads thrice per day. Statistically significant $(\mathrm{p}<0.05)$ relationship was observed between types of absorbent materials used during menstruation among public and private school girls. (Table 2)

Univariate analysis showed the difference of activities missed during menstruation among secondary and higher secondary school girls. Periods make you stay at home $1,089(54.5 \%)$ with crude OR $=1.36,95 \%$ confidence interval $(\mathrm{CI})=1.13-1.63, P<0.001$; periods make you unable to conduct daily activities 1,083 (54\%) with $\mathrm{OR}=1.60,95 \% \mathrm{CI}=1.33-1.93, P<0.001$; adolescent girls who take regular baths during periods $1,102(55 \%)$ with $\mathrm{OR}=1.23,95 \% \mathrm{CI}=1.02-1.48$, $P<0.05$; these variables were positively associated
Multivariable analysis reveals that the variables; periods make you stay at home, periods make you unable to conduct daily activities and periods make you unable to walk far; have been found to be significantly associated with secondary and higher secondary school students. After adjustment, the significance of these variables were adjusted as follows: $\mathrm{OR}=1.24,95 \%$ $\mathrm{CI}=1.01-1.52, \mathrm{p}<0.05 ; \mathrm{OR}=1.58,95 \% \mathrm{CI}=1.29$ $-1.93, P<0.001$; and $\mathrm{OR}=0.70,95 \% \mathrm{CI}=0.58-$ $0.85, P<0.001$. (Table 3 )

\section{DISCUSSION}

In this study, the mean age at menarche was found to be $12.5 \pm 1.2$ years, which is consistent with other findings of Kumar NP study, which is $12.6 \pm 1.08$ years $^{16}$.

The study shows that the menstrual knowledge among young girls was adequate and most of the participants $89.7 \%$ knew that menstruation is a physiological process, and $71.3 \%$ knew that the blood comes from the womb, nevertheless $42 \%$ believed that menstrual 
Menstrual hygiene practices among adolescent school girls

Table 2: Types of Absorbent Materials Used During Menstruation Among Public and Private School Girls

\begin{tabular}{|l|c|c|c|c|c|c|c|c|}
\hline \multicolumn{9}{|c|}{ Absorbent Material Using During Periods } \\
\hline n $(\%)$ & Cloths/Towels & Sanitary pads & Cotton & Toilet papers & Mattress (Foam) & Any other & Total & p-value \\
\hline Public & $345(27.1)$ & $830(65.3)$ & $46(3.6)$ & $20(1.6)$ & $26(2.0)$ & $5(0.4)$ & $1272(100.0)$ & \\
Private & $107(14.7)$ & $541(74.3)$ & $38(5.2)$ & $12(1.6)$ & $23(3.2)$ & $7(1.0)$ & $728(100.0)$ & $<0.001 *$ \\
\hline Total & $452(22.6)$ & $1371(68.6)$ & $84(4.2)$ & $32(1.6)$ & $49(2.5)$ & $12(0.6)$ & $2000(100.0)$ & \\
\hline
\end{tabular}

*p-value $<0.05$

Table 3: Difference of Activities Missed During Menstruation Among Secondary and Higher Secondary School Girls

\begin{tabular}{|c|c|c|c|c|c|}
\hline \multicolumn{2}{|l|}{ Activities During Monthly Cycle } & \multicolumn{2}{|c|}{ Univariable Analysis } & \multicolumn{2}{|c|}{ Multivariable Analysis } \\
\hline & & $\mathrm{OR}^{\mathrm{a}}(95 \% \mathrm{CI})$ & p-value & $\mathrm{OR}^{\mathrm{b}}(95 \% \mathrm{CI})$ & p-value \\
\hline \multirow{2}{*}{ Housework missed } & \# & 1 & & & \\
\hline & No & $1.11(0.92-1.34)$ & 0.240 & & \\
\hline \multirow{2}{*}{ Staying at home } & \# & 1 & & 1 & \multirow[b]{2}{*}{0.034} \\
\hline & No & $1.36(1.13-1.63)$ & $<0.001 *$ & $1.24(1.01-1.52)$ & \\
\hline \multirow[t]{2}{*}{ Unable to walk far } & $\#$ & 1 & & 1 & \multirow[b]{2}{*}{$<0.001 *$} \\
\hline & No & $0.81(0.68-0.98)$ & $0.034 *$ & $0.70(0.58-0.85)$ & \\
\hline \multirow[t]{2}{*}{ Unable to carry out daily activities } & $\#$ & 1 & & 1 & \multirow[b]{2}{*}{$<0.001 *$} \\
\hline & No & $1.60(1.33-1.93)$ & $<0.001 *$ & $1.58(1.29-1.93)$ & \\
\hline \multirow[t]{2}{*}{ Regular bathing } & \# & 1 & & & \\
\hline & No & $1.23(1.02-1.48)$ & $0.026^{*}$ & & \\
\hline
\end{tabular}

$\#=$ Reference category

$*$ p-value $<0.05$

$\mathrm{OR}_{\mathrm{b}}^{\mathrm{a}}=$ Crude Odds Ratio

$\mathrm{OR}^{\mathrm{b}}=$ Adjusted Odds Ratio

blood contained dangerous substances. Knowledge about menstruation was also found to be high in another survey as most of the adolescent girls $88.9 \%$ replied that menstrual blood is not harmful ${ }^{16}$. A previous study done in Pakistan revealed that $50 \%$ of the girls were deficient in their understanding of the source of menstrual blood ${ }^{15}$. Significant association has been observed between knowledge about menstruation among secondary and higher secondary school girls. Similar findings have been observed from studies in Ethiopia $^{18}$ and India ${ }^{19}$ showing that participants who were educated up to high school and above were more aware about menstruation.

Menstruation leads to absenteeism of school girls. In our study $17.5 \%$ participants missed one day per month and $19.3 \%$ missed two days per month from school during their periods and reasons were pain $54.5 \%$ and fear of staining clothes $18.4 \%$. Indian study in 2018 reported that $41.6 \%$ girls missed their school because of menstruation and the reasons were; lack of proper place to change or dispose sanitary pads in school 56\%, due to pain and discomfort $23.1 \%$ and due to fear of staining $18.1 \%^{16}$. However in other Indian studies, it was only $13.9 \%{ }^{20}$ and $12.6 \%{ }^{21}$ respectively.
It was found in this study that most of the girls $68.6 \%$ were using sanitary pads while $31.4 \%$ were using cloth/ towels or other absorbent material. Similar finding were recorded in an Indian study showing 94\% of girls used sanitary napkins during periods ${ }^{16}$. However, several studies revealed lower usage of sanitary pads $20.8 \%{ }^{22}, 34.7 \%^{23}$ and $15.7 \%^{20}$ and high usage of cloth $31.3 \%^{22}$ and $44.1 \%^{23}$. In our study, significant association was observed between types of absorbent material used by public and private school girls. West Bengal study also found higher use of sanitary pads among girls in urban schools compared to rural ones ${ }^{24}$. This was also found in this study that $35.2 \%$ girls changed pads three times per day, $32.9 \%$ two pads/day, and $11 \%$ changed pads once a day.

Study from Lebanon reported that $40.4 \%$ of adolescent girls changed sanitary pads for every 3 to 4 hours each day $^{25}$. In addition, study from Bengal showed that in $27 \%$ adolescent girls in urban and $30.4 \%$ in rural areas, the frequency of changing pads was only once per day $^{24}$. Routine menstruation affects housework 55.3\%, unable to walk far $56.5 \%$, girls stay at home during cycles $54.5 \%$ and $46 \%$ are unable to perform daily activities such as cooking. Other studies also revealed 
similar results $52 \%{ }^{16}, 60 \%^{26}$ and $54 \%^{27}$ respectively. Study from Bengal showed that $78 \%$ girls were restricted from household work ${ }^{24}$. However, other studies indicated that most girls faced various barriers and restrictions ${ }^{6,15}$.

Adolescent girls $44.9 \%$ bathed daily during periods. In contrast, a study conducted in Karachi showed that approximately $50 \%$ of the subjects were restricted from taking bath ${ }^{15}$. Another Indian study revealed that $84 \%$ adolescent girls bathed daily during their monthly menstruation cycle ${ }^{6}$.

\section{CONCLUSION}

The study revealed sufficient knowledge of menstrual hygiene among adolescent girls, but significant association was observed between menstrual hygiene practices among secondary and higher secondary school girls. Education regarding menstrual hygiene practices should be conveyed by the mothers of adolescent girls and schools should also include health education programmes in their curricula regarding better management of menstrual hygiene.

Authors' contribution: NM designed the study, analysed statistically and edited the manuscript. HT contributed to study design and data collection. IA, A, and IN worked on data collection and manuscript writing. SMM analysed and interpreted data, edited and proofread the manuscript.

\section{References}

1. Sommer M, Sahin M. Overcoming the taboo: advancing the global agenda for menstrual hygiene management for schoolgirls. Am J Public Health 2013;103:1556-9.

2. Karout N. Prevalence and pattern of menstrual problems and relationship with some factors among Saudi nursing students. J Nurs Educ Prac. 2015;5(12):1.

3. Mason L, Nyothach E, Alexander K, frank O,Eleveld A, Vulule J. et.al. 'We keep it secret so no one should know' - a qualitative study to explore young schoolgirls attitudes and experiences with menstruation in rural western Kenya. PLoS ONE. 2013;8:79132. https://doi. org/10.1371/journal.pone.0079132

4. McMahon SA, Winch PJ, Caruso BA, Obure AF, Ogutu EA, Ochari IA, et.al. 'The girl with her period is the one to hang her head' Reflections on menstrual management among schoolgirls in rural Kenya. BMC Int Health Hum Rights. 2011;11(1):7. doi: 10.1186/1472698X-11-7.

5. Patil VV, Udgiri R. Menstrual hygienic practices among adolescent girls of rural North Karnataka region, India. Int J Comm Med Public Health. 2016 ;3(7):1872-6. DOI: http://dx.doi.org/10.18203/2394-6040. ijcmph20162058
6. Van Eijk AM, Sivakami M, Thakkar MB, Bauman A, Laserson KF, Coates S, et.al. Menstrual hygiene management among adolescent girls in India: a systematic review and meta-analysis. BMJ Open. 2016;6(3):e010290. doi: 10.1136/bmjopen-2015-010290.

7. Das P, Baker KK, Dutta A, Swain T, Sahoo S,Das BS, et.al. Menstrual hygiene practices, WASH access and the risk of urogenital infection in women from Odisha, India. PLoS ONE 2015;10(6):e0130777. doi: 10.1371/ journal.pone.0130777.

8. United Nations, educational, scientific and cultural organization (UNESCO) (2014) Puberty education and menstrual hygiene management. Available: http:// unesdoc.unesco.org/images/0022/002267/226792e.pdfpuberty. Accessed April 25, 2018.

9. Mahon T, Fernandes M. Menstrual hygiene in South Asia: a neglected issue for WASH (water, sanitation and hygiene) programmes. Gender \& Development. 2010;18(1):99-113. https://doi.org/10. 1080/ 13552071003600083

10. Muralidharan A, Patil H, Patnaik S. Unpacking the policy landscape for menstrual hygiene management: implications for school Wash programmes in India. Waterlines 2015;34:79-91. doi:10.3362/17563488.2015.008.

11. Baisley K, Changalucha J, Weiss H, Mugeye K, Everett D, Hambleton I, et.al. Bacterial vaginosis in female facility workers in north-western Tanzania: prevalence and risk factors. Sexually transmitted infections. Randomized Controlled Trial. Sex Transm Infect. 2009. 85(5):370-5. doi:10.1136/sti.2008.035543.

12. Aniebue UU, Aniebue PN, Nwankwo TO. The impact of pre-monarchial training on menstrual practices and hygiene of Nigerian school girls. Pan Afr Med J. 2009;2(1).

13. Zegeye DT, Megabiaw B, Mulu A. Age at menarche and the menstrual pattern of secondary school adolescents in northwest Ethiopia. BMC Women's Health. 2009;9(1):29.doi: 10.1186/1472-6874-9-29.

14. Sarah H, Sue TM. A resource for improving menstrual hygiene around the world. Water Aid. 2012; 22-43.

15. Ali TS, Rizvi SN. Menstrual knowledge and practices of female adolescents in urban Karachi, Pakistan. J Adolesc.2010;33(4):531-41. doi: 10.1016/j.adolescence. 2009.05.013.

16. Kumar NP, Waghmare R. Menstrual hygiene practices among high school girls in field practice area of rural health and training centre.Indian J Res. 2018;7(4).

17. Guerry E. An assessment of menstrual hygiene practices and absenteeism in Western Uganda. Sheffield: University of Sheffield. 2013 Sep.

18. Upashe SP, Tekelab T, Mekonnen J. Assessment of knowledge and practice of menstrual hygiene among high school girls in Western Ethiopia. BMC Women's Health. 2015;15(1):84. doi: 10.1186/s12905-015-02457. 
19. Kansal S, Singh S, Kumar A. Menstrual hygiene practices in context of schooling: A community study among rural adolescent girls in Varanasi. Indian $\mathbf{J}$ Community Med. 2016;41(1):39. doi: 10.4103/09700218.170964.

20. Mudey AB, Kesharwani N, Mudey GA, Goyal RC. A cross-sectional study on awareness regarding safe and hygienic practices amongst school going adolescent girls in rural area of Wardha District, India. Glob J Health Sci. 2010;2(2):225. DOI:10.5539/gjhs.v2n2p225

21. Dambhare DG, Wagh SV, Dudhe JY. Age at menarche and menstrual cycle pattern among school adolescent girls in Central India. Glob J Health Sci. 2012;4(1):105. doi:10.5539/gjhs.v4n1p105.

22. Sarkar I, Dobe M, Dasgupta A, Basu R, Shahbabu B. Determinants of menstrual hygiene among school going adolescent girls in a rural area of West Bengal. J Family Med Prim Care. 2017;6(3):583. DOI: 10.4103/22494863.222054
23. Shanbhag D, Shilpa R, D'Souza N, Josephine P, Singh J, Goud BR. Perceptions regarding menstruation and practices during menstrual cycles among high school going adolescent girls in resource limited settings around Bangalore city, Karnataka, India. Int J Collab Res on Internal Med Public Health. 2012;4(7):1353.

24. Paria B, Bhattacharyya A, Das S. A comparative study on menstrual hygiene among urban and rural adolescent girls of west Bengal. J Family Med Prim Care. 2014;3(4):413-7. doi: 10.4103/2249-4863.148131.

25. Santina T, Wehbe N, Ziade FM, Nehme M. Assessment of beliefs and practices relating to menstrual hygiene of adolescent girls in Lebanon. Int J Health Sci Res. 2013;3(12):75-88.

26. Sharma P, Malhotra C, Taneja DK, Saha R. Problems related to menstruation amongst adolescent girls. Indian J Pediatr. 2008;75(2):125-9. doi: 10.1007/s12098-0080018-5.

27. Sharma A, Taneja DK, Sharma P, Saha R. Problems related to menstruation and their effect on daily routine of students of a medical college in Delhi, India. Asia Pac J Public Health. 2008; 20(3):234-41. doi: 10.1177/ 1010539508316939. 